\title{
Focusing on Internet Learning Psychology to Officers and Men, Promoting Military Professional Education Innovation and Development
}$$
\text { Yi He}{ }^{1,2, a} \text {, Xin } \mathrm{Li}^{2} \text { and Ze Yu }
$$ \\ ${ }^{1}$ Liaoning Normal University, Dalian, Liaoning, China \\ ${ }^{2}$ PLA Dalian Naval Academy, Dalian, Liaoning, China \\ alilyheyi@qq.com
}

\begin{abstract}
Keywords: Internet learning psychology; independent learning; lack of motivation; learning strategies; tendency

Abstract: Development of military professional education is a major measure to speed up and improve the three-in-one novel military talent training system. Online Internet course learning is the main form of military professional education. In this process, officers and men will probably witness psychological characteristics of blind selection of course resources, insufficient self-restraint, lack of motivation, and incomplete knowledge structure. It is necessary to effectively configure learning strategies to guide officers and men to study independently, and promptly feeding back and motivating their motivations, optimizing and integrating content designs, promoting internalization of their knowledge. In the process of education, it is necessary to avoid fast food, pan-entertainment and off-center tendencies.
\end{abstract}

\section{Introduction}

Development of military professional education is a major measure to implement the strategy of military enforcement with talents of the CPC Central Committee, Central Military Commission, and President Xi Jinping, accelerate development of military college education, military training and military professional education three-in-one systems, with its development constantly concerned by the CPC Central Committee and Central Military Commission. The Third Plenary Session of the 18th CPC Central Committee first put military professional education as an important component of the three-in-one novel military talent training system. In June 2014, the former four headquarters specifically issued Comments on Accelerating the Development of Military Professional Education, defining military professional education functional positioning, operating mechanism, teaching mode, management system and evaluation methods. In August 2017, the Central Military Commission issued Military Professional Education Reform Program, providing detailed descriptions of military professional education overall development ideas and objectives, main reform tasks and organizational implementation methods. At present, to have the main method of military professional education, namely large-scale online network courses, achieve practical results, it is necessary to have great concern of the leading organs and the improvement of various facilities, and study psychology of officers and men against the background of the Internet, making teaching contents and forms meet the needs of officers and men, effectively leading the learning direction and improving the efficiency of independent learning.

\section{Analysis of Psychological Characteristics and Causes of Network Learning for Officers and} Men

The form of military professional education is large-scale online network independent learning. Its effect is influenced by factors such as selection of learning materials, learning motivation, and

\footnotetext{
1 This article was aided by National Social Science Fund Military Research Project 2014 Research on Innovative Three-in-One Military Talent Training System, project number: 14GJ003-156.
} 
learning time.

\subsection{Insufficient guidance causing blindness in the selection of course resources}

Different from classroom teaching and practical training, military professional education mainly relies on online independent selection of resources by officers and men for learning. This is a way of learning that the educators are not present and officers and men are independent. At present, most educational institutions inside and outside the army focus on online education. And the Internet or online network courses are quite complicated. It is very difficult to make proper selection in such vast course information. In case the learner fails to have clear self-recognition or target orientation, the selection will become quite blind.

Development of military professional education is still at the stage centering on course resources. Guidance of effective application is seldom mentioned. Thus, some officers and men participating in the online course are more likely to follow the trend based on attention and network evaluation. And some even select courses according to their own familiarity and interest, avoiding unfamiliar ones. These selection criteria can not help them selecting courses truly meeting their post characteristics and career development needs, even leading them into "comfort zones". Such learning activities structure almost waste of time and fail to upgrade their competency.

\subsection{Insufficient collective influence causing insufficient self-restraint and motivation}

From a major perspective, military professional education forms a full-member, full-time, and full-range ubiquitous learning environment, with almost everyone, all the time and everywhere involving. From a small perspective, it is decentralized individual learning, different from class-based learning. The class-based learning environment makes learning activities influenced by teachers and other students present. Just as many people experience, working with others proves high efficient, namely effect of other's presence or social contribution in psychology. When people realize they belong to the same group as other people, they will have their words and deeds noticed by others in the group. In order to gain group acceptance, they will be restrained, tending to present better behavior.

Online independent study refers to individualized education, with study content different from that of officers and men sitting together, belonging to different groups psychologically, without group integration in subjective experience or comparison with others (or only needing comparison with other learners unknown online), without realistic group pressure, resulting in reduced self-restraint. Self-comparison has no pressure. Learning activities are not as easy and enjoyable as general online entertainment activities, requiring cognitive efforts. In case learning materials are not particularly attractive or urgently needed, learning motivation will be naturally insufficient.

\subsection{Time fragmentation causing learning incoherence and incoherent knowledge structure}

In order to solve the problems of "2 shortages" and "2 insufficiencies", the army constantly increases its training and learning tasks, constantly reducing free time of officers and men, making their learning time fragmented, and their learning activities interfered, incomplete and incoherent. According to the principles of learning psychology, the final results of learning refer to learner's new knowledge structure, namely a neural network connection generated by repeating the same activity. If learning activities are often interfered and disrupted, the connection at cranial nerves are difficult to form or are not solid, the knowledge structure is naturally incomplete, and the learning effect is not achieved.

At present, the grass-roots units of the army have tight schedules and heavy tasks. The time spent by officers and men at each post is relatively short. In a limited period of time, recalling what was learned last time and re-entering the learning state will take up a large part. The more fragmented the learning time is, the greater the number of interruptions, the greater the total time spent on recollecting and reentering the learning state, and the less time actually spent on effective learning will be. In this way, officers and men can only understand new knowledge as much as possible, and it is impossible to establish links between various knowledge points. The complete knowledge 
structure is naturally difficult to form.

\section{Strengthening and Improving Military Professional Education Against Network Learning Psychology of officErs and Men}

Blindness of learning content selection, insufficient learning motivation, and incomplete knowledge structure of officers and men in network learning seriously challenge effective military professional education. To this end, it is necessary to strengthen and improve military professional education in the following aspects;

\subsection{Effectively configuring learning strategies to guide independent learning}

Learning strategies refer to learner's effective learning plans, methods, techniques, and control methods in learning activities. Research shows there is a close relationship between learning strategies and academic performance. Effective learning strategies directly affect learner's achievements. Against network learning, due to vast resources and mixed information, it is particularly important to effectively adopt and configure learning strategies. In general, there are 3 learning strategies: cognitive strategy, meta-cognitive strategy and resource management strategy. Cognitive strategy is the methods and techniques applied by officers and men against specific learning tasks. Officers and men learn a specific course, the methods of retelling, taking notes, compiling outlines, and making the knowledge structure network map, structuring the cognitive strategy. The meta-cognitive strategy is the planning, monitoring and adjustment of the cognitive strategy. It is the perception and control of officers and men with their own specific learning methods and techniques, without centering on any specific content. It mainly includes setting goals, self-checking, adjusting reading speed, and focusing. The resource management strategy is the management and adjustment of the learning environment, time and external support. Effective learners can effectively manage themselves, actively coordinating their peripheral resources, acting on their own learning activities and promoting learning efficiency.

These learning strategies are centering on different aspects and levels of learning, needing effective configuration based on learning objectives and their own characteristics. In general, relying on cognitive strategy at the beginning will be effective. With learning process, the latter two strategies will be adopted, which is an objective need and the results of active exploration. Both factors promote each other. The more complex and extensive the content of learning is, the more meta-cognitive strategies and resource management strategies will be needed; and the more basic knowledge and stronger ability will be understood, the higher meta-cognitive strategies and resource management will be applied in learning activities. Therefore, against the background that the officers and men of our army generally have certain knowledge, it is more important not to learn but how to learn. To achieve practical results in military professional education, it is necessary to increase awareness of officers and men on the importance of learning strategies against the background of the Internet, and teach them how to rationally deploy and apply learning strategies.

\subsection{Conducting prompt learning feedback, stimulating learning motivation}

Based on the characteristics of military professional education network independent learning, officers and men are in most cases "individual learning", and learning activities require moving away from "comfort zones" into "learning zones", requiring great psychological efforts. Frequent withdrawals and laziness need constant learning motivation. According to behavioral psychology, when people's behavior gets timely and positive feedback (affirmation or reward), it will be easy to continue to repeat the behavior. At present, prompt feedback and continuous upgrading mechanism of multiple network games is the application of the principles. In military professional education network course, it is necessary conduct prompt and positive feedback for officers and men, making them intuitively view their own learning results and appreciate their progress, maintaining expectation and motivation for learning tasks and active learning adjustment. 
In this regard, it is proper to refer to multiple Internet education APP practices. For example, designs of various courses arrange videos, audios, and manuscripts, and multiple minor questions to discuss in the instant message area, and additional links to expand reading, making it easier for officers and men to master. In addition, the number of times officers and men play audios and videos in the course, the number of text readings, and speeches can be quantified, with appropriate rewards so as to motivate their motivation. In view of insufficient group influence and social comparison of network learning, it is proper to divide mutual assistance groups according to tasks for group learning, making separate learners discuss and solve problems together, developing an atmosphere similar to classroom discussion, enhancing group influence. And it is proper to establish virtual communities for comparisons, achieving learning activities and achievements rankings, making officers and men generate social comparisons and stimulate achievements motivation.

\subsection{Optimizing and integrating content design, promoting knowledge internalization}

Fragmented learning activities in military professional education make it more important to integrate knowledge content and promote its internalization for officers and men. Integration refers to logically summing up and refining new knowledge points, making them easier to remember and extract. Internalization focuses on convergence of old and new knowledge, making new knowledge actually absorbed as a part of the original cognitive structure, and promoting continuous upgrading of the cognitive structure. Cognitive psychology believes the results of learning activities refer to the change in the cognitive structure, presenting as mastery of new knowledge and behavioral methods. To facilitate this process, designs of course contents must be conducive to the integration and internalization of knowledge.

According to cognitive psychology related theories, in learning content designs, it is necessary to have them modular to facilitate retrieval and extraction. Minds are naturally sensitive to contents with complete boundaries and logics. For the contents of network courses, it is necessary to highlight their respective complete boundaries. Each of the best contents is a complete sample including questions and solutions. Each of the large contents includes $7 \pm 2$ sub-contents (human brain working memory capacity is $7 \pm 2$ units of information). It is necessary to connect with the past work and life experience of officers and men, promoting convergence of the cognitive structure. With the familiar content as the starting point, minds can transfer the existing experience in the cognitive structure, promoting understanding of new knowledge, and finally integrating it with the original structure, having the knowledge truly internalized.

\section{Military Professional Education Unfavorable Tendencies}

It is necessary to notice that military professional education activities focusing on network online education are quite different from Internet activities of officers and men. In implementation, it is necessary to avoid the following unfavorable tendencies:

\subsection{Fast-food tendency caused by excessive brief, frequent and fast characteristics}

To make it easier for officers and men to use limited spare time to carry out their learning, the military professional education network courses focus on short and refine characteristics. But it is necessary to avoid loss of necessary essences due to limitations and the fast-food tendency of officers and men. The video time of each network course is usually more than a dozen minutes, and the introduction to certain complex knowledge point and argumentation in general classroom teaching requires such a time period. Too short time will repeatedly simplify the contents of the course, even leaving only a few principles for officers and men to memorize, and having the demonstration process abbreviated, making them often fail to seek real understanding, centering on remembering instead of thinking, resulting in "understanding only approximately the how, not the why". In order to ensure the integrity of the course system, the designers try to put all kinds of knowledge on it. They seem to have a wide range. However, each one is only a little touched, far from thoroughly, like beans on the porcelain plate, scattered and unconnected. If they are only 
content to receive such information quickly and in large quantities, officers and men will be similar to take non-nutritious fast food, prone to indigestion. If they want to obtain the knowledge, they need to read additional materials. Otherwise, they will fall into simplistic thinking situation.

\subsection{Pan-entertainment tendency caused by excessive diversity}

Due to the characteristics of network multimedia, network courses will apply as many media tools as possible. However, the format will eventually serve the content. Selection of all information transmission channels must follow scientific and moderate standards, preventing pan-entertainment tendency for new forms and diversity. In the traditional society, there are important differences between learning activities and entertainment activities. Learning activities are always linked with curiosity, overcoming difficulties and obtaining new knowledge. Entertainment activities are intended to bring people comfort and happiness without much mental effort. Against the cyber society, the boundary between the two gradually becomes blurred. Edutainment is generally recognized by society. However, its ultimate goal is to "teaching". Excessive "entertainment" may even affect "teaching". Cognitive psychology studies have found the diversification of information-carrying channels is not directly proportional to learning efficiency. When too many channels of information are applied, it can lead to distractions, cognitive overload and decreased learning efficiency. "Having little sometimes means having more." In the implementation of military professional education, it is necessary to keep in mind education's enlightening and leading functions, selecting the most appropriate way of information presenting, avoiding pan-entertainment tendency caused by excessive forms influencing content acceptance.

\subsection{Decentralization tendency caused by excessive course subjectivity}

The role of military professional education in the three-in-one novel military talent training system is "expansion and support". It is necessary to focus on the army and fighting, army development and growth of officers and men. Civilian colleges implement large-scale open courses, focusing on the basic knowledge system of learners or social groups and subject contents, characterized by knowledge popularization. Military professional education centers on cultivation of military talents, meeting the needs of military changes, post requirements and career development. Military professional education must focus on officers and men. Network courses must focus on targeted audience groups and posts, avoiding the tendency to seek for excessive integrity and deviate from the central task of the troops. At present, multiple military professional education courses offered by many military academies make classroom teaching networked, failing to design novel teaching contents for officers and men based on their characteristics. "Offering what are available" and the teaching methods obviously fail to meet the requirements of military professional education. In order to enhance military professional education, educators of military academies must get familiar with the characteristics of military missions and actual needs of officers and men, combining them with their own teaching theories, making officers and men subjects of teaching activities in accordance with laws and characteristics of network learning, developing and implementing targeted courses for officers and men.

\section{References}

[1] Publicity Department of the CPC Central Committee: General Secretary Xi Jinping Series Important Addresses, Learning Press, 2014

[2] Former Four Headquarters: Comments on Accelerating Development of Military Professional Education. 2014

[3] The CPC Central Military Commission: Reform Implementation Program of Military Professional Education, 2017

[4] Web Application Psychology, Edited by Zheng Zheng, et al. Science Press, 2007

[5] Cognitive Psychology, [USA] Robert L. Sorso, Translated by He Hua, Jiangsu Education 
Publishing House, 2010

[6] Learning Theory. Zhang Qi, Hubei Education Press, 1999

[7] Psychology and Life, [USA] Richard Grieg, Philip Zimbardo, Posts and Telecom Press, 2003 